\title{
STRATEGI PENGUATAN BMT BERDASARKAN PERILAKU PEDAGANG DI PASAR TRADISIONAL
}

\author{
Safaah Restuning Hayati \\ Universitas Muhammadiyah Yogyakarta \\ restuninghayati@yahoo.com
}

\begin{abstract}
Abstrak
Paper ini bertujuan untuk menemukan strategi penguatan BMT melalui segmentasi pasar. Populasi dalam penelitian ini adalah pedagang di pasar tradisional yang berada di wilayah karisidenan Surakarta. Menggunakan dasar teori marketingmix untuk jasa. Teknik pengambilan sampel menggunakan accidental sampling. Jumlah responden 60 pedagang. Teknik analisis data menggunakan analisis cluster. Data primer dikumpulkan melalui kuesioner dan diolah menggunakan SPSS 23. Hasil olah data menemukan 3 segmen/cluster, di mana masing-masing segmen memiliki faktor pertimbangan berbeda dalam memutuskan untuk mengajukan pembiayaan di BMT. Strategi utama yang harus dilakukan BMT adalah meningkatkan literasi keuangan syariah bagi pedagang di pasar tradisional dan membuat inovasi produk pembiayaan yang sesuai dengan kondisi pedagang yang unbankable.
\end{abstract}

Kata Kunci: BMT, Segmentasi Pasar, Perilaku Konsumen, Pasar Tradisional 


\section{A. PENDAHULUAN}

Jumlah UMKM di Indonesia diperkirakan sebanyak 55 juta. Sebesar 45 persen atau 22 juta di antaranya berperan sebagai pedagang di pasar tradisional. Dapat dibayangkan betapa banyak rakyat Indonesia yang bertahan hidup dari tempat yang becek dan kumuh tersebut. Menjadi pedagang memang relatif lebih mudah, karena tingkat pendidikan tidak menjadi prasyarat bidang usaha ini. Krisis ekonomi berdampak pada peningkatan jumlah pedagang di pasar tradisional secara signifikan. Peningkatan ini terjadi karena mereka yang pekerja dan pegawai terkena Pemutusan Hubungan Kerja (PHK), pelajar/mahasiswa yang putus sekolah, atau para pencari kerja yang kesulitan mendapatkan pekerjaan. Namun, kebanyakan dari mereka mengalami keterbatasan modal baik untuk pengadaan barang dagangan ataupun sewa kios.

Data terbaru tahun 2016 menunjukkan jumlah UMKM mengalami penurunan, BPS menyebutkan jumlah total UMK (Usaha Mikro dan Kecil) 26.263.649 dan total UMB (Usaha Menengah dan Besar) 447.352. Jumlah UMK terbanyak berada di pulau Jawa yaitu sebesar 59,65\% atau 15.931.889. Sedangkan jumlah UMK paling sedikit berada di pulau Maluku dan Papua yaitu 1,69\% atau $451.874 .^{2}$ Mayoritas UMK mengalami kendala utama yang sama, yaitu modal.

Menteri Koperasi dan UMKM dalam pidatonya di International Conference on Religion, Microfinance, and Empowerment pada 20 Juli 2017 di Universitas Muhammadiyah Yogyakarta menegaskan tentang pentingnya keberadaan UMKM di Indonesia karena mampu menyerap tenaga kerja sebesar 96,99\%. Namun, kontribusi UMKM di sektor ekspor masih sangat rendah, yaitu 1,3\%. Hal ini dilatarbelakangi oleh rendahnya daya saing UMKM terdadap produk usaha besar dan produk impor. Berdasarkan keprihatinan ini, BMT sebagai salah satu lembaga keuangan mikro dapat mengoptimalkan perannya melalui pemberdayaan UMKM.

Salah satu cara pemberdayaan UMKM yaitu melalui pemberian pinjaman dan pendampingan usaha. Penelitian ini fokus kepada UMKM yang berada di pasar tradisional, karena $45 \%$ dari seluruh pelaku UMKM di Indonesia berada di sana. Hal ini menjadi peluang bagi BMT agar dapat memberdayakan UMKM, khususnya pedagang kecil di pasar tradisional. Namun, di sisi lain BMT juga memiliki masalah dan kendala. Menurut Ridwan, ${ }^{3}$ kelemahan BMT pada umumnya adalah SDM, fasilitas, service, dan permodalan, yang

${ }^{1}$ Herman Malano, Selamatkan Pasar Tradisional, (Jakarta: Gramedia Pustaka Utama, 2011), 172-173.

2Badan Pusat Statistik, "Jumlah Usaha/Perusahaan Menurut Skala Usaha dan Pulau, 2016 Indonesia” diakses tanggal $11 \quad$ Juli 2017 dari http://se2016.bps.go.id/Listing/index.php/site/tabel?tid=5\&wid=0.

${ }^{3}$ Ahmad Hasan Ridwan, Manajemen Baitul Mal wa Tamwil, (Bandung: Pustaka Setia, 2013), 66 
berakhir pada sulitnya menumbuhkan kepercayaan masyarakat luas (public trust) terhadap jasa dan pelayanan yang dapat diberikan oleh BMT. Oleh karena itu, yang paling penting dan dibutuhkan BMT tidak sekedar gagasan dan konsep saja, namun juga aksi nyata.

Untuk menarik pelaku UMKM di pasar tradisional, maka BMT harus membuat terobosan-terobosan yang sesuai dengan kebutuhan dan minat pedagang di pasar tradisional. Hal ini juga bertujuan agar BMT semakin kuat dan tidak kembang kempis. Untuk itu, BMT perlu mengetahui kebutuhan dan minat pedagang di pasar tradisional dalam mengembangkan usahanya. BMT juga perlu melakukan segmentasi pasar dan penetrasi pasar. Hal ini bertujuan agar produk yang dimiliki BMT semakin kuat dan tepat sasaran, sehingga diminati para pedagang di pasar tradisional. Selain itu, agar BMT semakin bersinar dan mampu bersaing dengan lembaga keuangan mikro konvensional, bahkan dengan lembaga perbankan yang membuka layanan mikro di sekitar pasar tradisional.Setelah menemukan apa saja kebutuhan dan minat pedagang (UMKM) terkait pembiayaan dan pendampingan usaha, selanjutnya dibuat segmentasi pasar dan strategi penguatan BMT untuk menarik UMKM.

\section{B. METODOLOGI}

Paper ini termasuk dalam jenis penelitian kuantitatif-deskriptif. Penelitian deskriptif merupakan penelitian yang dilakukan untuk mengetahui nilai variabel mandiri, baik satu variabel atau lebih, tanpa menghubungkannya dengan variabel lain. ${ }^{4}$ Jenis data yang digunakan adalah data primer yang dikumpulkan dengan instrumen kuesioner. Beberapa kebaikan kuesioner adalah dalam waktu pendek dapat menghubungi banyak orang dan data yang terkumpul selalu dapat diperiksa kembali. ${ }^{5}$ Selanjutnya data diolah menggunakan Statistical Product and Service Solutions (SPSS).

Berdasarkan metode yang digunakan, paper ini termasuk dalam penelitian survei. Menurut Kerlinger (1973), sebagaimana dikutip oleh Rochaety dari bukunya Sugiyono, menyatakan bahwa penelitian survei merupakan penelitian yang dilakukan pada populasi besar atau kecil, tetapi data yang dipelajari merupakan data sampel yang diambil dari populasi tersebut. Hasil dari penelitian survei dapat digeneralisasi dan hasilnya lebih akurat jika menggunakan sampel yang representatif. ${ }^{6}$ Selain survei, penelitian ini juga menggunakan teknik pengumpulan data wawancara dan observasi. Wawancara

${ }^{4}$ Ety Rochaety dkk, Metodologi Penelitian Bisnis dengan Aplikasi SPSS, Edisi Revisi (Jakarta: Mitra Wacana Media, 2009), 17.

${ }^{5}$ Hendri Tanjung dan Abrista Devi, Metodologi Penelitian Ekonomi Islam, (Jakarta: Gramata Publishing, 2013), 80.

${ }^{6}$ Sugiyono dkk, Statistika untuk Penelitian dan Aplikasinya dengan SPSS 10,10, (Bandung: Alfabeta, 2002) dalam Ety Rochaety dkk, Metodologi Penelitian Bisnis dengan Aplikasi SPSS, Edisi Revisi (Jakarta: Mitra Wacana Media, 2009), 15-16. 
digunakan sebagai upaya untuk melakukan konfirmasi kepada responden dan melengkapi data yang sebelumnya dikumpulkan dengan kuesioner. Sedangkan observasi digunakan untuk melihat dari dekat kondisi fisik objek penelitian, dalam hal ini kondisi fisik barang dagangan dan tempat berdagang di pasar tradisional. ${ }^{7}$

Populasi penelitian ini adalah pedagang di pasar tradisional yang berada di wilayah Karisidenan Surakarta. Enam pasar yang ada di wilayah Solo Raya yaitu pasar Kartasura di Kabupaten Sukoharjo, pasar Tegal Gondo di Kabupaten Klaten, pasar Colomadu di Kabupaten Karanganyar, pasar Pengging di Kabupaten Boyolali, pasar Masaran di Kabupaten Sragen, dan pasar Jongke di Kota Surakarta.

Teknik mengambilan sampel menggunakan accidental sampling, yaitu teknik penentuan sampel berdasarkan kebetulan, yaitu siapa saja yang secara kebetulan bertemu dengan peneliti dan layak dijadikan sumber data. ${ }^{8}$ Keunggulan teknik ini adalah berguna untuk peramalan-peramalan tertentu, sampel terjamin dapat memenuhi tujuan yang spesifik. ${ }^{9}$

Menurut Roscoe, ukuran sampel yang layak untuk penelitian adalah antara 30 sampai dengan 500 orang. ${ }^{10}$ Dari enam pasar tradisional yang ada di wilayah Solo Raya, masing-masing diambil 10 pegadang dengan kriteria belum memiliki kios sendiri dan belum pernah mengajukan pinjaman atau pembiayaan di lembaga keuangan manapun. Total responden 60 orang.

Cara untuk menentukan skor dalam penelitian ini dalah dengan menggunakan skala Likert. $^{11}$ Jangka responsiyang lebih besar membuat skala Likert dapat memberikan keterangan yang lebih nyata dan jelas tentang sikap responden. ${ }^{12}$ Aturan skoring dalam penelitian ini adalah 5-4-3-2-1 : SS (Sangat Setuju), S (Setuju), N (Netral), TS (Tidak Setuju), STS (Sangat Tidak Setuju).

Teknik analisis data yang digunakan untuk menganalisis data dalam penelitian ini adalah analisis cluster. Analisis cluster bertujuan untuk mengelompokkan variabel-variabel yang memiliki kesamaan karakteristik, yaitu dengan mengelompokkan berdasarkan baris. Analisis cluster yang dipakai menggunakan metode K-Means Cluster. Metode ini untuk memproses semua indikator yang digunakan dalam segmentasi atau peng-cluster-an secara bersamaan. Proses ini

${ }^{7}$ Etta Mamang Sangadji dan Sopiah, Perilaku Konsumen: Pendekatan Praktis (Yogyakarta: ANDI, 2013), 346.

8Ety Rochaety dkk, Metodologi Penelitian Bisnis dengan Aplikasi SPSS, Edisi Revisi (Jakarta: Mitra Wacana Media, 2009), 65.

${ }^{9}$ Hendri Tanjung dan Abrista Devi, Metodologi Penelitian Ekonomi Islam, (Jakarta: Gramata Publishing, 2013), 117 dan 119.

${ }^{10}$ Sugiyono, Metode Penelitian Bisnis, (Bandung: Alfabeta, 2012), 172.

${ }^{11}$ Masri Singarimbun dan Sofian Effendi, Metode Penelitian Survai (Jakarta: Pustaka LP3ES Indonesia, 2008), 111.

12Moh. Nazir, Metodologi Penelitian (Bogor: Ghalia Indonesia, 2005), 340. 
dimulai dengan menentukan jumlah cluster terlebih dahulu, setelah itu melakukan clustering. ${ }^{13}$ Beberapa uji yang termasuk dalam analisis cluster dan digunakan dalam penelitian ini adalah uji Cross Tabs dan uji Chi-Square.

Penelitian ini terkait dengan perilaku konsumen dan landasan teori yang digunakan adalah marketing mix atau bauran pemasaran, yaitu 4P (product, prize, place, promotion). Khusus untuk bauran pemasaran dalam produk jasa terdiri dari tujuh komponen, yaitu product, prize, place, promotion, people, process dan customer service. $^{14}$ Dalam penelitian ini ditambahkan satu komponen yaitu psychological (psikologi). Menurut Sangadji, faktor psikologi mencakup motivasi, persepsi, pembelajaran, sikap/kepercayaan. Sikap dan kepercayaan merupakan faktor psikologis yang mempengaruhi keputusan pembelian konsumen. ${ }^{15}$

Tabel 1. Indikator dan Jumlah Butir

\begin{tabular}{|c|l|c|}
\hline No & \multicolumn{1}{|c|}{ Indikator } & Butir \\
\hline 1 & Product & 3 \\
\hline 2 & Prize & 3 \\
\hline 3 & Place & 2 \\
\hline 4 & Promotion & 2 \\
\hline 5 & People & 2 \\
\hline 6 & Process & 2 \\
\hline 7 & Customer Service & 2 \\
\hline 8 & Psycological & 4 \\
\hline \multicolumn{2}{|c|}{ Total } & 20 \\
\hline
\end{tabular}

\section{TEMUAN DAN PEMBAHASAN}

\section{Segmentasi Pasar BMT}

Data primer yang berasal dari 60 angket yang disebarkan kepada 60 pedagang di pasar tradisional yang berada di enam kabupaten telah diolah menggunakan SPSS 23. Hasil segmentasi pasar BMT berdasarkan perilaku pedagang dapat dilihat dalam tabel Final Cluster Centers berikut:

Tabel 2. Final Cluster Centers

\begin{tabular}{|l|r|r|r|}
\hline \multirow{2}{*}{} & \multicolumn{3}{|c|}{ Cluster } \\
\cline { 2 - 4 } & 1 & \multicolumn{1}{|c|}{2} & \multicolumn{1}{c|}{3} \\
\hline Product & 13,08 & 8,29 & 10,68 \\
Prize & 11,67 & 9,47 & 10,42 \\
\hline
\end{tabular}

${ }^{13}$ Freddy Rangkuti, Marketing Strategy \& Competitive Positioning, (Jakarta: Gramedia Pustaka Utama, 2011), 89 dan 113.

${ }^{14}$ Rambat Lupiyoadi dan A. Hamdani, Manajemen Pemasaran Jasa (Jakarta: Salemba Empat, 2008), 70-71.

${ }^{15}$ Etta Mamang Sangadji dan Sopiah, Perilaku Konsumen: Pendekatan Praktis (Yogyakarta: ANDI, 2013), 24. 


\begin{tabular}{l|r|r|r|} 
Place & 8,04 & 7,18 & 7,84 \\
Promotion & 7,96 & 7,76 & 7,00 \\
Process & 8,33 & 8,18 & 7,89 \\
CS & 7,79 & 7,24 & 7,00 \\
Psychological & 14,46 & 14,88 & 10,37 \\
\hline
\end{tabular}

Sumber: Output SPSS 23

Berdasarkan output tersebut, maka terbentuk tiga segmen calon konsumen BMT dengan karakteristik yang berbeda. Tipe konsumen pada segmen satu adalah calon konsumen yang mengajukan pembiayaan ke BMT karena (1) faktor psikologi dan (2) produk BMT. Faktor psikologi meliputi motivasi, persepsi, proses belajar, kepercayaan dan sikap. Motivasi calon konsumen BMT dalam mengajukan pembiayaan adalah untuk menambah modal usaha dan membeli/menyewa kios. Persepsi yang melandasi mereka ingin mengajukan pembiayaan adalah persepsi positif bahwa BMT memberikan akses keuangan dengan tidak membedakan status sosial. Jadi, meskipun mereka mayoritas unbankable tetap dapat mengajukan pembiayaan.

Faktor psikologi selanjutnya adalah proses belajar. Calon konsumen ingin mengajukan pembiayaan karena rasa ingin tahu lebih mendalam tentang BMT dan produk-produknya. Hal ini terkonfirmasi melalui wawancara tidak terstruktur saat di lapangan bahwa mayoritas responden belum mengenal keuangan syariah, khususnya BMT. Sehingga saat mengumpulkan data primer, peneliti sekaligus melakukan sosialisasi singkat terkait dengan BMT. Faktor psikologi yang keempat adalah kepercayaan dan sikap. Setelah diberi sosialisasi singkat, calon konsumen mulai paham dengan BMT. Mereka ingin memilih BMT karena BMT tidak menggunakan sistem bunga dan percaya sistem ini membawa kebaikan.

Faktor kedua yang mendorong calon konsumen mengajukan pembiayaan di BMT adalah salah satu bagian dari marketingmix yaitu product (produk BMT). Peneliti mencoba merancang suatu produk pembiayaan yang sesuai dengan kebutuhan dan kondisi pedagang kecil di pasar tradisional. Setelah rancangan tersebut disodorkan kepada calon konsumen BMT, tanggapan mereka positif. Produk pembiayaan yang diajukan adalah pembiayaan yang tidak memerlukan agunan. Hal ini mengingat mayoritas pedagang kecil di pasar tradisional kesulitan menyediakan barang yang dapat dijaminkan, seperti BPKB motor, sertifikat tanah, dan lain sebagainya. Yang dapat menjadi jaminan dalam pembiayaan ini adalah kepercayaan yang dibangun antara konsumen dan BMT. Untuk meminimalisir terjadinya pembiayaan bermasalah, maka BMT dapat menerapkan sistem tanggung renteng. Untuk membuat diversifikasi produk, pembiayaan ini disertai asuransi jiwa dan 
asuransi kesehatan. Hal ini membuat produk BMT semakin menarik dan sangat menguntungkan bagi konsumen. Saat mereka sakit atau meninggal dunia, keluarga yang bersangkutan mendapat keringanan dari segi biaya dan santunan.

Berbeda dengan segmen satu, pada segmen dua ini hanya ada satu faktor utama yang mempengaruhi calon konsumen untuk mengajukan pembiayaan di BMT yaitu faktor psikologi. Selanjutnya pada segmen tiga, terdapat tiga faktor yang mendorong calon konsumen mengajukan pembiayaan di BMT yaitu faktor produk (product), harga (prize), dan psikologi (psychological). Untuk faktor produk dan psikologi sudah dijelaskan pada segmen satu dan segmen dua. Sedangkan faktor harga (prize) meliputi tiga indikator, yaitu nisbah bagi hasil besar, angsuran ringan, dan gratis biaya administrasi.

Setelah terbentuk tiga segmen, selanjutnya perlu diketahui apakah variabel-variabel yang telah membentuk segmen tersebut mempunyai perbedaan pada setiap segmen. Hal ini dapat dianalisis dari output SPSS berikut:

Tabel 3. ANOVA

\begin{tabular}{|l|r|r|r|r|r|r|}
\hline & \multicolumn{2}{|c|}{ Cluster } & \multicolumn{2}{c|}{ Error } & \\
\cline { 2 - 6 } & Mean Square & Df & Mean Square & df & F & Sig. \\
\hline Product & 115,233 & 2 & 2,306 & 57 & 49,961 &, 000 \\
Prize & 24,725 & 2 & 2,249 & 57 & 10,993 &, 000 \\
Place & 3,889 & 2 & 1,262 & 57 & 3,081 &, 054 \\
Promotion & 5,191 & 2 &, 702 & 57 & 7,395 &, 001 \\
Process & 1,028 & 2 & 1,502 & 57 &, 685 &, 508 \\
CS & 3,583 & 2 & 1,351 & 57 & 2,652 &, 079 \\
Psychological & 119,020 & 2 & 3,055 & 57 & 38,957 &, 000 \\
\hline
\end{tabular}

Sumber: Output SPSS 23

Berdasarkan tabel di atas, diketahui nilai $F$ terbesar suatu variabel yang nilai signifikansinya kurang dari 0,05 adalah variabel product $(49,961)$. Hal ini berarti bahwa variabel produk semakin memiliki perbedaan pada ketiga segmen yang terbentuk. Dengan kata lain, faktor produk sangat membedakan karakteristik dari ketiga segmen. Sedangkan nilai $\mathrm{F}$ terkecil adalah variabel process, yaitu 0,685 . Faktor proses tidak memiliki perbedaan pada masingmasing segmen. Bahkan perbedaan tersebut sudah tidak ada lagi karena nilai signifikansinya di atas 0,05 yaitu 0,508. Variabel yang tidak menyebabkan perbedaan pada masing-masing segmen adalah variabel proses (sig. 0,508), CS/customerservice (sig. 
0,079), dan place/lokasi (sig. 0,054). Sedangkan variabel lainnya merupakan variabel-variabel yang menyebabkan terjadinya perbedaan antar segmen.

Tahap berikutnya dapat diketahui sebaran responden pada ketiga segmen yang telah terbentuk melalui tabel berikut:

Tabel 4. Number of Cases in

each Cluster

\begin{tabular}{|ll|r|}
\hline Cluster & 1 & 24,000 \\
& 2 & 17,000 \\
& 3 & 19,000 \\
& & 60,000 \\
Valid & &, 000 \\
Missing &
\end{tabular}

Sumber: Output SPSS 23

Berdasarkan tabel di atas, terlihat bahwa responden terbanyak berada pada segmen (cluster) satu. Sedangkan responden paling sedikit berada pada cluster/segmen dua. Jumlah anggota yang ada di setiap cluster dapat menjadi salah satu pertimbangan dalam menentukan target pasar. Namun, cluster yang mempunyai jumlah responden terbanyak belum tentu lebih potensial dibandingkan dengan cluster lain yang jumlah respondennya di bawahnya. Untuk mendalami target pasar ini, lebih lanjut dilakukan analisis Cross tabulasi.

\section{Profiling Masing-Masing Segmen (Cluster)}

Profiling masing-masing segmen dilakukan menggunakan analisis Cross tabulasi. Analisis ini bertujuan untuk mengetahui segmen mana yang paling menarik untuk dijadikan target pasar. Analisis ini menghubungkan antara variabel profil responden sebagai variabel independen dengan lokasi segmen (cluster membership). Namun, sebelum menganalisis Cross tabulasi, terlebih dahulu melihat hasil Chi-Square Tests.

\section{Analisis Cross Tabs Jenis Kelamin dengan Pilihan Segmen}

Berikut ini adalah hasil analisis Chi-Square Tests dan Cross Tabs untuk variabel jenis kelamin:

Tabel 5. Chi-Square Tests

\begin{tabular}{|c|c|c|c|}
\hline & Value & $\mathrm{df}$ & $\begin{array}{c}\text { Asymptotic } \\
\text { Significance (2- } \\
\text { sided) }\end{array}$ \\
\hline $\begin{array}{l}\text { Pearson Chi-Square } \\
\text { Likelihood Ratio } \\
\text { Linear-by-Linear Association } \\
\mathrm{N} \text { of Valid Cases }\end{array}$ & $\begin{array}{r}, 538^{\mathrm{a}} \\
, 541 \\
, 112 \\
60\end{array}$ & $\begin{array}{l}2 \\
2 \\
1\end{array}$ & $\begin{array}{l}, 764 \\
, 763 \\
, 738\end{array}$ \\
\hline
\end{tabular}

Sumber: Output SPSS 23 
Berdasarkan tabel Chi-Square di atas, nilai Pearson ChiSquare lebih kecil dibandingkan dengan nilai Chi-Square table. Pearson Chi-Square nilainya 0,538 dan Asymp. Sig 2 adalah 0,764. $\mathrm{Hal}$ ini berarti Ho diterima. Artinya, tidak ada hubungan yang signifikan antara jenis kelamin dengan pilihan segmen. Selanjutnya hasil analisis Cross Tabs dapat dilihat pada tabel berikut ini:

Tabel 6. Crosstab



Sumber: Output SPSS 23

Selanjutnya berdasarkan tabel Cross Tabs di atas, secara keseluruhan dari hubungan jenis kelamin dengan pilihan segmen dapat diketahui bahwa segmen satu paling banyak dipilih karena presentasenya paling besar yaitu 58,3\%. Sedangkan segmen tiga dan segmen dua masing-masing $31,7 \%$ dan $28,3 \%$. Dari tabel tersebut dapat diketahui bahwa segmen satu lebih disukai oleh perempuan $(58,3 \%)$, demikian juga untuk segmen dua $(64,7 \%)$ dan segmen tiga (52,6\%). Sedangkan laki-laki yang menyukai segmen satu $(41,7 \%)$ jumlahnya hampir sama dengan laki-laki yang menyukai segmen tiga $(47,4 \%)$. Sedikit responden laki-laki yang memilih segmen dua.

\section{Analisis Cross Tabs Usia dengan Pilihan Segmen}

Berikut ini adalah hasil analisis Chi-Square Tests dan Cross

Tabs untuk variabel usia:

Tabel 7. Chi-Square Tests

\begin{tabular}{|c|c|c|c|}
\hline & Value & $d f$ & $\begin{array}{c}\text { Asymptotic } \\
\text { Significance (2- } \\
\text { sided) }\end{array}$ \\
\hline $\begin{array}{l}\text { Pearson Chi-Square } \\
\text { Likelihood Ratio } \\
\text { Linear-by-Linear Association } \\
\mathrm{N} \text { of Valid Cases }\end{array}$ & $\begin{array}{r}5,298^{\mathrm{a}} \\
5,571 \\
, 003 \\
60\end{array}$ & $\begin{array}{l}6 \\
6 \\
1\end{array}$ & $\begin{array}{l}, 506 \\
, 473 \\
, 958\end{array}$ \\
\hline
\end{tabular}

Sumber: Output SPSS 23 
Berdasarkan tabel Chi-Square di atas, nilai Pearson ChiSquare lebih besar dibandingkan dengan nilai Chi-Square table. Pearson Chi-Square nilainya 5,298 dan Asymp. Sig 2 adalah 0,506. Hal ini berarti Ho ditolak. Artinya, terdapat hubungan yang sangat signifikan antara usia dengan pilihan segmen. Selanjutnya hasil analisis Cross Tabs dapat dilihat pada tabel di bawah ini:

Tabel 8. Crosstab

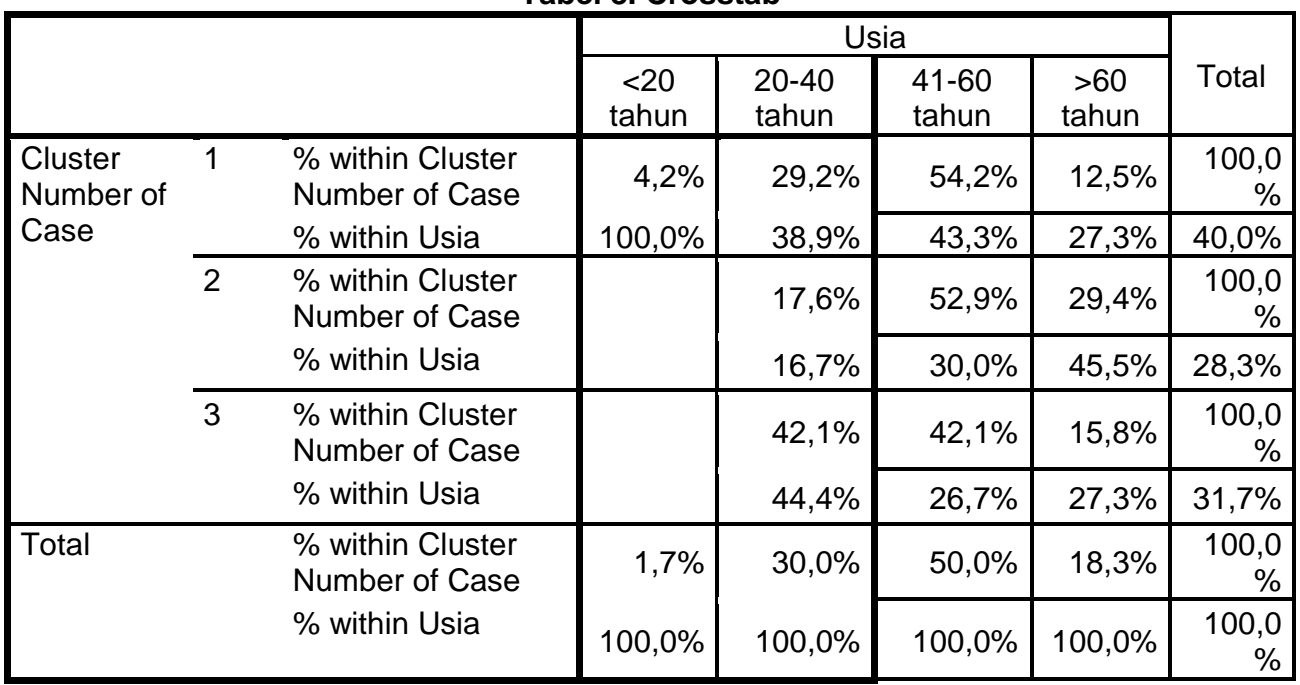

Sumber: Output SPSS 23

Tabel di atas menunjukkan bahwa segmen yang paling banyak dipilih adalah segmen satu karena presentasenya paling besar yaitu $40 \%$. Kelompok usia paling banyak berapa pada usia 41 tahun sampai 60 tahun (50\%). Sedangkan usia paling sedikit berada pada usia di bawah 20 tahun. Usia 20 tahun sampai 40 tahun lebih menyukai segmen tiga. Sedangkan usia 41 tahun sampai 60 tahun lebih menyukai segmen satu. Untuk usia di atas 60 tahun lebih menyukai segmen dua.

\section{Analisis Cross Tabs Pendidikan dengan Pilihan Segmen}

Berikut ini adalah hasil analisis Chi-Square Tests dan Cross Tabs untuk variabel tingkat pendidikan:

Tabel 9. Chi-Square Tests

\begin{tabular}{|c|c|c|c|}
\hline & Value & $\mathrm{df}$ & $\begin{array}{c}\text { Asymptotic } \\
\text { Significance (2- } \\
\text { sided) }\end{array}$ \\
\hline $\begin{array}{l}\text { Pearson Chi-Square } \\
\text { Likelihood Ratio } \\
\text { Linear-by-Linear Association } \\
\mathrm{N} \text { of Valid Cases }\end{array}$ & $\begin{array}{r}9,493^{\mathrm{a}} \\
10,182 \\
3,039 \\
60\end{array}$ & $\begin{array}{l}6 \\
6 \\
1\end{array}$ & $\begin{array}{l}148 \\
, 117 \\
, 081\end{array}$ \\
\hline
\end{tabular}

Sumber: Output SPSS 23

Berdasarkan tabel Chi-Square di atas, nilai Pearson ChiSquare lebih besar dibandingkan dengan nilai Chi-Square table. Pearson Chi-Square nilainya 9,493 dan Asymp. Sig 2 adalah 0,148. Hal ini berarti Ho ditolak. Artinya, terdapat hubungan yang sangat 
signifikan antara tingkat pendidikan dengan pilihan segmen. Selanjutnya hasil analisis Cross Tabs dapat dilihat pada tabel di bawah ini:

Tabel 10. Crosstab

\begin{tabular}{|c|c|c|c|c|c|c|c|}
\hline & \multicolumn{4}{|c|}{ Pendidikan } & \multirow{2}{*}{ Total } \\
\hline & & & $<S D$ & SD & SMP & SMA & \\
\hline \multirow{6}{*}{$\begin{array}{l}\text { Cluster } \\
\text { Number } \\
\text { of Case }\end{array}$} & 1 & $\begin{array}{l}\% \text { within Cluster } \\
\text { Number of Case }\end{array}$ & $16,7 \%$ & $25,0 \%$ & $29,2 \%$ & $29,2 \%$ & $100,0 \%$ \\
\hline & & $\%$ within Pendidikan & $21,1 \%$ & $37,5 \%$ & $50,0 \%$ & $63,6 \%$ & $40,0 \%$ \\
\hline & 2 & $\begin{array}{l}\% \text { within Cluster } \\
\text { Number of Case }\end{array}$ & $41,2 \%$ & $41,2 \%$ & $11,8 \%$ & $5,9 \%$ & $100,0 \%$ \\
\hline & & $\%$ within Pendidikan & $36,8 \%$ & $43,8 \%$ & $14,3 \%$ & $9,1 \%$ & $28,3 \%$ \\
\hline & 3 & $\begin{array}{l}\% \text { within Cluster } \\
\text { Number of Case }\end{array}$ & $42,1 \%$ & $15,8 \%$ & $26,3 \%$ & $15,8 \%$ & $100,0 \%$ \\
\hline & & $\%$ within Pendidikan & $42,1 \%$ & $18,8 \%$ & $35,7 \%$ & $27,3 \%$ & $31,7 \%$ \\
\hline \multirow{2}{*}{\multicolumn{2}{|c|}{ Total }} & $\begin{array}{l}\% \text { within Cluster } \\
\text { Number of Case }\end{array}$ & $31,7 \%$ & $26,7 \%$ & $23,3 \%$ & $18,3 \%$ & $100,0 \%$ \\
\hline & & $\%$ within Pendidikan & $100,0 \%$ & $100,0 \%$ & $100,0 \%$ & $100,0 \%$ & $100,0 \%$ \\
\hline
\end{tabular}

\section{Sumber: Output SPSS 23}

Tabel 9 di atas menjelaskan bahwa segmen yang paling banyak dipilih oleh responden adalah segmen satu karena presentasenya paling besar (40\%). Responden paling banyak $(31,7 \%)$ memiliki tingkat pendidikan kurang dari SD, artinya tidak lulus SD atau tidak sekolah. Pola tingkat pendidikan ini berjalan ke kanan, misalnya responden terbanyak kedua adalah lulusan SD dan terbanyak ketiga adalah lulusan SMP. Segmen satu disukai oleh mereka yang memiliki tingkat pendidikan SMP $(29,2 \%)$ dan SMA (29,2\%). Segmen dua disukai oleh mereka yang lulusan SD $(41,2 \%)$ dan tidak sekolah $(41,2 \%)$. Sedangkan segmen tiga disukai oleh responden yang tidak mengenyam pendidikan atau tidak lulus SD.

\section{Analisis Cross Tabs Barang Dagangan dengan Pilihan Segmen}

Berikut ini adalah hasil analisis Chi-Square Tests dan Cross Tabs untuk variabel jenis barang dagangan:

Tabel 11. Chi-Square Tests

\begin{tabular}{|c|c|c|c|}
\hline & & & $\begin{array}{c}\text { Asymptotic } \\
\text { Significance (2- } \\
\text { sided) }\end{array}$ \\
\hline Pearson Chi-Square & $7,651^{\mathrm{a}}$ & 6 &, 265 \\
Likelihood Ratio & 7,773 & 6 &, 255 \\
Linear-by-Linear Association &, 851 & 1 &, 356 \\
N of Valid Cases & 60 & & \\
\hline
\end{tabular}

Sumber: Output SPSS 23

Berdasarkan tabel Chi-Square di atas, nilai Pearson ChiSquare lebih besar dibandingkan dengan nilai Chi-Square table. Pearson Chi-Square nilainya 7,651 dan Asymp. Sig 2 adalah 0,265. Hal ini berarti Ho ditolak. Artinya, terdapat hubungan yang signifikan antara jenis barang dagangan dengan pilihan segmen. 
Selanjutnya hasil analisis Cross Tabs dapat dilihat pada tabel di bawah ini:

Tabel 12. Crosstab

\begin{tabular}{|c|c|c|c|c|c|c|c|}
\hline & \multicolumn{4}{|c|}{ Dagangan } & \multirow[b]{2}{*}{ Total } \\
\hline & & & $\begin{array}{c}\text { Buah } \\
\text { dan } \\
\text { Sayur }\end{array}$ & $\begin{array}{c}\text { Ikan dan } \\
\text { Daging }\end{array}$ & $\begin{array}{c}\text { Semba } \\
\text { ko }\end{array}$ & Lainnya & \\
\hline \multirow{6}{*}{$\begin{array}{l}\text { Cluster } \\
\text { Number } \\
\text { of Case }\end{array}$} & \multirow[t]{2}{*}{1} & $\begin{array}{l}\% \text { within Cluster } \\
\text { Number of Case }\end{array}$ & & & $8,3 \%$ & $54,2 \%$ & $100,0 \%$ \\
\hline & & $\%$ within Dagangan & $42,1 \%$ & $12,5 \%$ & $22,2 \%$ & $54,2 \%$ & $40,0 \%$ \\
\hline & \multirow[t]{2}{*}{2} & $\begin{array}{l}\text { \% within Cluster } \\
\text { Number of Case }\end{array}$ & $35,3 \%$ & $11,8 \%$ & $17,6 \%$ & $35,3 \%$ & $100,0 \%$ \\
\hline & & $\%$ within Dagangan & $31,6 \%$ & $25,0 \%$ & $33,3 \%$ & $25,0 \%$ & $28,3 \%$ \\
\hline & \multirow[t]{2}{*}{3} & $\begin{array}{l}\% \text { within Cluster } \\
\text { Number of Case }\end{array}$ & $26,3 \%$ & $26,3 \%$ & $21,1 \%$ & $26,3 \%$ & $100,0 \%$ \\
\hline & & $\%$ within Dagangan & $26,3 \%$ & $62,5 \%$ & $44,4 \%$ & $20,8 \%$ & $31,7 \%$ \\
\hline \multirow{2}{*}{\multicolumn{2}{|c|}{ Total }} & $\begin{array}{l}\% \text { within Cluster } \\
\text { Number of Case }\end{array}$ & $31,7 \%$ & $13,3 \%$ & $15,0 \%$ & $40,0 \%$ & $100,0 \%$ \\
\hline & & $\%$ within Dagangan & $100,0 \%$ & $100,0 \%$ & $\begin{array}{r}100,0 \\
\%\end{array}$ & $100,0 \%$ & $100,0 \%$ \\
\hline
\end{tabular}

Sumber: Output SPSS 23

Pada tabel Cross Tabs di atas terlihat bahwa segmen paling sedikit diminati adalah segmen dua, sebesar 28,3\%. Responden didominasi (40\%) oleh pedagang selain sayur-buah, ikang-daging, dan sembako. Misalnya pedagang kelapa dan es dawet. Jenis barang dagangan terbanyak kedua yang dijual oleh responden adalah buah dan sayur, yaitu sebesar $31,7 \%$. Pedagang buahsayur lebih menyukai segmen satu (33,3\%) dan segmen dua $(35,3 \%)$. Pedagang ikan-daging lebih menyukai segmen tiga $(26,3 \%)$, sama dengan pedagang sembako yang lebih menyukai segmen tiga $(21,1 \%)$. Untuk pedagang lain-lain menyukai segmen satu $(54,2 \%)$.

\section{Analisis Cross Tabs Lokasi Pasar dengan Pilihan Segmen}

Berikut ini adalah hasil analisis Chi-Square Tests dan Cross Tabs untuk variabel lokasi pasar:

Tabel 13. Chi-Square Tests

\begin{tabular}{|l|r|r|r|}
\hline & & & \multicolumn{2}{|c|}{$\begin{array}{c}\text { Asymptotic } \\
\text { Significance (2- } \\
\text { sided) }\end{array}$} \\
\hline Pearson Chi-Square & Value & Df & 108 \\
Likelihood Ratio & $15,711^{\text {a }}$ & 10 &, 047 \\
Linear-by-Linear Association & 2,1527 & 10 &, 142 \\
N of Valid Cases & 60 & 1 & \\
\hline
\end{tabular}

Sumber: Output SPSS 23

Berdasarkan tabel Chi-Square di atas, nilai Pearson ChiSquare lebih besar dibandingkan dengan nilai Chi-Square table. Pearson Chi-Square nilainya 15,711 dan Asymp. Sig 2 adalah 
0,108 . Hal ini berarti Ho ditolak. Artinya, terdapat hubungan yang signifikan antara lokasi pasar dengan pilihan segmen. Selanjutnya hasil analisis Cross Tabs dapat dilihat pada tabel di bawah ini:

Tabel 14. Crosstab

\begin{tabular}{|c|c|c|c|c|c|c|c|c|c|}
\hline & \multicolumn{6}{|c|}{ Lokpas } & \multirow[b]{2}{*}{ Total } \\
\hline & & & $\begin{array}{c}\text { Kartas } \\
\text { ura }\end{array}$ & $\begin{array}{c}\text { Jongk } \\
\mathrm{e}\end{array}$ & $\begin{array}{l}\text { Tegal } \\
\text { Gondo }\end{array}$ & $\begin{array}{c}\text { Coloma } \\
\text { du }\end{array}$ & $\begin{array}{c}\text { Penggi } \\
\text { ng }\end{array}$ & $\begin{array}{l}\text { Masar } \\
\text { an }\end{array}$ & \\
\hline \multirow{6}{*}{$\begin{array}{l}\text { Cluster } \\
\text { Number } \\
\text { of Case }\end{array}$} & \multirow[t]{2}{*}{1} & $\begin{array}{l}\% \text { within Cluster } \\
\text { Number of Case }\end{array}$ & $16,7 \%$ & $16,7 \%$ & $33,3 \%$ & $4,2 \%$ & $20,8 \%$ & $8,3 \%$ & $\begin{array}{r}100,0 \\
\% \\
\end{array}$ \\
\hline & & $\%$ within Lokpas & $40,0 \%$ & $40,0 \%$ & $80,0 \%$ & $10,0 \%$ & $50,0 \%$ & $20,0 \%$ & $40,0 \%$ \\
\hline & \multirow[t]{2}{*}{2} & $\begin{array}{l}\% \text { within Cluster } \\
\text { Number of Case }\end{array}$ & $17,6 \%$ & $23,5 \%$ & $11,8 \%$ & $17,6 \%$ & $11,8 \%$ & $17,6 \%$ & $\begin{array}{r}100,0 \\
\%\end{array}$ \\
\hline & & $\%$ within Lokpas & $30,0 \%$ & $40,0 \%$ & $20,0 \%$ & $30,0 \%$ & $20,0 \%$ & $30,0 \%$ & $28,3 \%$ \\
\hline & \multirow[t]{2}{*}{3} & $\begin{array}{l}\text { \% within Cluster } \\
\text { Number of Case }\end{array}$ & $15,8 \%$ & $10,5 \%$ & & $31,6 \%$ & $15,8 \%$ & $26,3 \%$ & $\begin{array}{r}100,0 \\
\% \\
\end{array}$ \\
\hline & & \% within Lokpas & $30,0 \%$ & $20,0 \%$ & & $60,0 \%$ & $30,0 \%$ & $50,0 \%$ & $31,7 \%$ \\
\hline \multirow[t]{2}{*}{ Total } & & $\begin{array}{l}\% \text { within Cluster } \\
\text { Number of Case }\end{array}$ & $16,7 \%$ & $16,7 \%$ & $16,7 \%$ & $16,7 \%$ & $16,7 \%$ & $16,7 \%$ & $\begin{array}{r}100,0 \\
\% \\
\end{array}$ \\
\hline & & $\%$ within Lokpas & $\begin{array}{r}100,0 \\
\%\end{array}$ & $\begin{array}{r}100,0 \\
\%\end{array}$ & $\begin{array}{r}100,0 \\
\%\end{array}$ & $100,0 \%$ & $\begin{array}{r}100,0 \\
\%\end{array}$ & $\begin{array}{r}100,0 \\
\%\end{array}$ & $\begin{array}{r}100,0 \\
\%\end{array}$ \\
\hline
\end{tabular}

Sumber: Output SPSS 23

Tabel 13 menunjukkan bahwa segmen yang paling diminati adalah segmen satu dan paling sedikit peminatnya yaitu segmen dua. Pedagang di pasar Kartasura terpecah menjadi tiga segmen (masing-masing $16,7 \%, 17,6 \%$, dan $15,8 \%$, semua segmen jumlah peminatnya hampir sama. Untuk pedagang di pasar Jongke lebih menyukai segmen dua. Sedangkan pedagang di pasar Tegal Gondo sama sekali tidak meminati segmen tiga. Mayoritas dari mereka menyukai segmen satu (33,3\%). Untuk pedagang di pasar Colomadu menyukai segmen tiga (31,6\%). Pedagang di pasar Pengging 20,8\% menyukai segmen satu. Selanjutnya pedagang di pasar Masaran mayoritas berada di segmen tiga (26,3\%). Berdasarkan analisis ini, maka dapat dikatakan bahwa meskipun berada dalam satu regional karisidenan Surakarta dan memiliki budaya yang sama, namun para pedagang di pasar tradisional berada di segmen yang berbeda-beda.

\section{Analisis Setiap Segmen (Cluster)}

\section{a. Cluster 1}

Cluster satu disukai baik oleh perempuan (58,3\%) ataupun laki-laki $(41,7 \%)$. Usia yang memilih segmen ini mayoritas berada pada kisaran 41 tahun sampai 60 tahun yaitu sebanyak 54,2\%. Pendidikan tertinggi yang menyukai cluster ini mayoritas SMP dan SMA (29,2\%). Pedagang yang berada pada cluster ini kebanyakan menjual buah dan atau sayur, yaitu sebesar 33,3\% dan terbesar adalah pedagang lain-lain (54,2\%) selain buahsayur, ikan-daging, dan sembako. Mereka yang berada di cluster ini didominasi dari pasar yang berlokasi di Pengging kabupaten 
Boyolali, yaitu sebesar 20,8\% dan berlokasi di Tegal Gondo kabupaten Klaten yaitu 33,3\%.

Kesimpulannya, konsumen yang memilih cluster satu adalah konsumen yang mempunyai usia matang (41-60 tahun) dibandingkan dengan dua cluster lainnya. Selain itu, konsumen memiliki tingkat pendidikan terakhir SMP dan SMA. Tingkat pendidikan ini lebih tinggi dibandingkan dengan tingkat pendidikan konsumen yang berada pada cluster lain. Berdasarkan karakteristik yang telah dipaparkan, maka dapat diduga konsumen pada cluster ini adalah pedagang yang berusia matang, cukup terpelajar, bisa baca tulis, melek keuangan syariah, dan secara geografis berada di sebelah barat dan selatan kota Surakarta.

\section{b. Cluster 2}

Cluster dua disukai oleh perempuan yaitu sebesar $64,7 \%$. Peminat laki-laki pada cluster ini hanya $35,3 \%$ atau hampir separuh dari peminat perempuan. Mayoritas berusia di atas 60 tahun $(29,4 \%)$. Didominasi pedagang buah dan sayur $(35,3 \%)$. Tingkat pendidikan rendah yaitu $41,2 \%$ lulus SD dan $41,2 \%$ (juga) tidak lulus SD. Dari keenam pasar yang menjadi lokasi penelitian, responden terbanyak yang masuk dalam kategori ini berasal dari pasar Jongke kota Surakarta.

Kesimpulannya, konsumen yang menyukai cluster dua adalah berjenis kelamin perempuan, berusia tua, dan tingkat pendidikan rendah dibanding dengan peminat pada cluster satu. Berdasarkan karakteristik tersebut, konsumen pada cluster dua dapat diduga kurang melek keuangan syariah dan secara geografis berada di kota Surakarta.

\section{c. Cluster 3}

Konsumen yang menyukai cluster tiga terdiri dari perempuan $(52,6 \%)$ dan laki-laki $(47,4 \%)$. Mayoritas masih tergolong muda, antara 20 tahun sampai 40 tahun. Dari segi pendidikan, konsumen cluster ini pendidikannya sangat rendah, yaitu $42,1 \%$ tidak lulus SD. Kebanyakan konsumen cluster tiga berjualan ikan dan daging (26,3\%) serta sembako (21,1\%). Konsumen yang menyukai cluster tiga sebagian besar berasal dari pasar Colomadu kabupaten Karanganyar (31,6\%) dan pasar Masaran kabupaten Sragen (26,3\%).

Kesimpulannya, konsumen yang berada dalam cluster ini imbang antara laki-laki dan perempuan, dengan usia yang masih muda dan produktif. Namun, tingkat pendidikannya rendah. Berdasarkan karakteristik yang telah dipaparkan, maka dapat diduga konsumen cluster tiga tidak melek huruf dan tidak melek keuangan syariah. Secara geografis, konsumen ini berada di sebelah utara dan timur kota Surakarta. 


\section{Rumusan Strategi Penguatan BMT}

Strategi yang harus segera dilakukan oleh BMT adalah meningkatkan literasi keuangan syariah khususnya di kalangan pedagang di pasar tradisional. Hal ini untuk menjawab faktor yang menjadi pertimbangan ketiga cluster di atas dalam mengajukan pembiayaan adalah faktor psikologi. Faktor psikologi meliputi motivasi, persepsi, proses belajar, dan keyakinan. Faktor ini menjadi positif jika para calon konsumen BMT benar-benar mengetahui sistem keuangan syariah dan pembiayaan berbasis bagi hasil. Mereka perlu diberikan sosialisasi secara mendalam tentang bagi hasil dan bunga. Sebab, kenyataan di lapangan banyak responden yang tidak mau tahu apa itu bagi hasil. Mereka menganggap sama saja dengan bunga.

Strategi yang kedua adalah untuk menjawab faktor produk (product) dan harga (prize) sebagai pertimbangan calon konsumen pada cluster satu dan cluster tiga. Jawabannya adalah, BMT harus membuat inovasi dan terobosan baru terkait dengan kebutuhan dan kondisi mereka. Model pembiayaan yang sesuai dengan pedagang kecil di pasar tradisional adalah pembiayaan yang tidak memerlukan jaminan, pembiayaan yang disertai fasilitas asuransi jiwa dan kesehatan. Untuk harga (prize), BMT dapat menawarkan bagi hasil yang menarik, membuat skema agar angsuran terasa ringan (misalnya angsuran dibayar mingguan), dan BMT harus mampu menggratiskan biaya adminstrasi saat pengajuan pembiayaan.

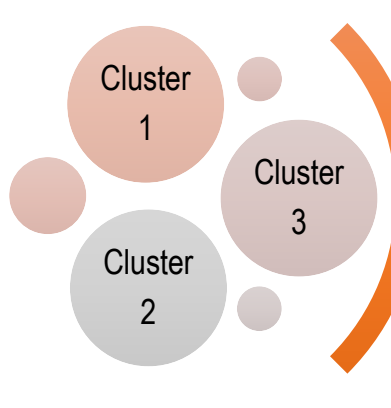

Segmentasi Pasar

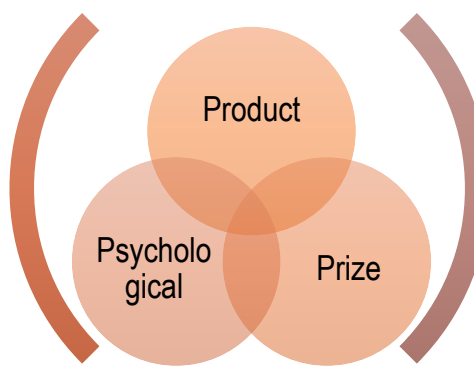

Faktor Penentu



Strategi Penguatan

\section{Gambar 1. Proses Perumusan Strategi Penguatan BMT}

Strategi ini sejalan dengan tiga konsep dasar pengembangan BMT, yaitu: (1) menjadikan BMT sebagai lembaga keuangan mikro syariah yang profesional dan dapat dipercaya sehingga dapat dijadikan tempat bagi proses akumulasi modal dari 
kalangan masyarakat bawah. Dalam hal ini jargon small but profesional penting dijadikan sebagai dasar pijakan. (2) menjadikan BMT sebagai fasilitator dan ujung tombak penggerak ekonomi sektor riil dengan menumbuhkan dan mengembangkan usaha kecil masyarakat bawah melalui perannya sebagai sumber permodalan yang mudah dan murah. (3) membangun jaringan (networking), baik secara horizontal-dengan sesama BMT dan lembaga-lembaga perekonomian lain-maupun secara vertikal dengan menjalin hubungan kemitraan (partnership) dengan LKS-LKS yang lebih besar dan lebih mapan, sebagai alternatif bagi pembinaan permodalan, manajemen dan SDM sekaligus berdasarkan prinsip kerja sama saling menguntungkan. ${ }^{16}$

\section{KESIMPULAN DAN IMPLIKASI}

Hasil analisis data dengan analisis cluster menemukan tiga segmentasi pasar yang terbentuk dari pegadang di pasar tradisional, yang diasumsikan sebagai calon konsumen BMT. Tiga segmen atau cluster tersebut yaitu:

1) Cluster Satu

Konsumen pada cluster ini menjadikan faktor produk (product) dan psikologi (psychological) sebagai landasan dalam mengambil keputusan pengajuan pembiayaan di BMT. Berdasarkan analisis cross tabs diduga konsumen pada cluster ini adalah pedagang yang berusia matang, cukup terpelajar, bisa baca tulis, melek keuangan syariah, dan secara geografis berada di sebelah barat dan selatan kota Surakarta.

2) Cluster Dua

Konsumen pada cluster ini menjadikan faktor psikologi (psychological) sebagai bahan pertimbangan utama dalam mengajukan pembiayaan di BMT. Berdasarkan analisis cross tabs, konsumen pada cluster dua ini diduga mayoritas sudah tua, sebagian tidak melek huruf, kurang melek keuangan syariah dan secara geografis berada di kota Surakarta.

3) Cluster Tiga

Konsumen pada cluster tiga dalam membuat keputusan untuk mengajukan pembiayaan di BMT memperhatikan tiga faktor, yaitu produk (product), harga (prize), dan psikologi (psychological). Berdasarkan analisis cross tabs, diduga konsumen cluster tiga ini tidak melek huruf dan tidak melek keuangan syariah. Secara geografis, konsumen ini berada di sebelah utara dan timur kota Surakarta.

${ }^{16}$ Ahmad Hasan Ridwan, Manajemen Baitul Mal wa Tamwil, (Bandung: Pustaka Setia, 2013), $66-67$. 
Strategi yang harus segera dilakukan oleh BMT adalah (1) meningkatkan literasi keuangan syariah khususnya di kalangan pedagang di pasar tradisional. Hal ini untuk menjawab faktor yang menjadi pertimbangan ketiga cluster di atas dalam mengajukan pembiayaan adalah faktor psikologi. Startegi selanjutnya, (2) BMT harus membuat inovasi dan terobosan baru terkait dengan kebutuhan dan kondisi mereka. Model pembiayaan yang sesuai dengan pedagang kecil di pasar tradisional adalah pembiayaan yang tidak memerlukan jaminan, pembiayaan yang disertai fasilitas asuransi jiwa dan kesehatan. Untuk harga (prize), BMT dapat menawarkan bagi hasil yang menarik, membuat skema agar angsuran terasa ringan (misalnya angsuran dibayar mingguan). 


\section{DAFTAR PUSTAKA}

Badan Pusat Statistik, "Jumlah Usaha/Perusahaan Menurut Skala Usaha dan Pulau, 2016 Indonesia" diakses tanggal 11 Juli 2017 dari http://se2016.bps.go.id/Listing/ index. php/site/tabel?tid=5\&wid=0.

Lupiyoadi, Rambat dan A. Hamdani. Manajemen Pemasaran Jasa. Jakarta: Salemba Empat, 2008.

Malano, Herman. Selamatkan Pasar Tradisional. Jakarta: Gramedia Pustaka Utama, 2011.

Nazir, Moh. Metodologi Penelitian. Bogor: Ghalia Indonesia, 2005.

Pradhana, Heppy Prasetyo dan Muhammad Nafik. "Penguatan Modal Usaha Mikro, Kecil dan Menengah Melalui Pembiayaan di BMT Mandiri Sejahtera Gresik" diakses dari http://ejournal.unair.ac.id/index.php/JESTT/article/viewFile/3350/2393tan ggal 25 Agustus 2017.

Rangkuti, Freddy. Marketing Strategy \& Competitive Positioning. Jakarta: Gramedia Pustaka Utama, 2011.

Ridwan, Ahmad Hasan. Manajemen Baitul Mal Wa Tamwil. Bandung: Pustaka Setia, 2013.

Rochaety, Ety dkk. Metodologi Penelitian Bisnis dengan Aplikasi SPSS. Edisi Revisi. Jakarta: Mitra Wacana Media, 2009.

Sangadji, Etta Mamang dan Sopiah. Perilaku Konsumen: Pendekatan Praktis. Yogyakarta: ANDI, 2013.

Simamora, Bilson. Riset Pemasaran: Falsafah, Teori, dan Aplikasi. Jakarta: Gramedia Pustaka Utama, 2004.

Singarimbun, Masri dan Sofian Effendi. Metode Penelitian Survai. Jakarta: Pustaka LP3ES Indonesia, 2008.

Sugiyono dkk. Statistika untuk Penelitian dan Aplikasinya dengan SPSS 10,10. Bandung: Alfabeta, 2002. Metode Penelitian Bisnis. Bandung: Alfabeta, 2012.

Tanjung, Hendri dan Abrista Devi. Metodologi Penelitian Ekonomi Islam. Jakarta: Gramata Publishing, 2013. 